\title{
Projeto de estruturação terminológica para a área de turismo e hospitalidade: um tesauro de definições
}

\author{
Marília Köenig - Doutoranda em Ciências da Linguagem. Faculdade de Tecnologia Senac Tubarão - Brasil. maiam 78@hotmail.com \\ Cláudia Nandi Formentin - Doutora em Ciências da Linguagem. Faculdade de Tecnologia Senac Tubarão - Brasil. formentinnandi.claudia@gmail.com \\ Renato Justino Borges - Mestre em Educação. Faculdade de Tecnologia Senac Tubarão - Brasil. renato.justino@sc.senac.br
}

\section{RESUMO}

O presente artigo contém a apresentação dos diversos termos (definições) usados na área de turismo e hotelaria. No referencial teórico investiu-se no levantamento de uma pesquisa na área das terminologias. Considerou-se importante apresentar as diferenças entre definição, conceito e significado, optando-se, por constituir um tesauro de definições, especificando a estrutura terminológica técnico-científica compondo um corpus teórico comum nos meios de hospedagem, com o propósito de construir um tesauro próprio à utilização no PIC Senac. A pesquisa baseia-se em diversas fontes de informação escrita (livros, artigos, dicionários). O Tesauro não é um trabalho com um fim determinado. Ao contrário, a partir do momento que se edifica um Tesauro, o mesmo deve estar sempre atualizado pelo fato de os termos e os significados estarem em constante transformação.

Palavras-chave: Tesauro. Pesquisa. Definição. Hospedagem.

\section{Terminological structuring project for the area of tourism and hospitality: a thesaurus of definitions}

\begin{abstract}
This article presents the definitions of different terms used in the area of tourism and hospitality. As theoretical reference a research in the field of terminologies was carried out. We considered important to point out the difference between definition, concept and meaning and therefore we have created a thesaurus of definitions specifying the terminological technical and scientific structure for terms, thus composing a theoretical common body for the area of accommodation aiming at building a thesaurus which is to be used by PIC SENAC. The research is based on various sources of written information (books, articles, dictionaries). The thesaurus is not a work with determined end. On the contrary, when a thesaurus is created, it has to be updated as terms and meanings are in constant transformation.
\end{abstract}

Keywords: Thesaurus. Research. Definition. Accommodation. 


\section{INTRODUÇÃO}

O Programa de Iniciação Científica - PIC SENAC Santa Catarina, de 2014 a 2016, está desenvolvendo um projeto de pesquisa que visa sistematizar os termos utilizados na área do turismo e hospitalidade, objetivando subsidiar profissionais ou consumidores no que se refere ao acesso de informações relacionadas a essa área de atuação. A esse conjunto de termos próprios ou relativos a um determinado campo do conhecimento ou a uma área de especificidade denominase terminologia ou tesauro.

Este artigo tem como objetivo atingir por meio de uma pesquisa elaborada e com um tesauro estruturado a compreensão dos termos de modo que, para o cliente interno, ou seja, profissionais que compõem o ambiente de trabalho representados, em geral, por diretores, gerentes, recepcionistas, dentre outros profissionais possam efetivamente se apropriar das terminologias relativas às suas práticas profissionais. Além dos clientes internos, também o tesauro poderá beneficiar os clientes externos que se relacionam de algum modo com as empresas do meio hoteleiro. Tendo presente a necessidade de construção do Tesauro, vimos como importante identificar, selecionar, analisar e tratar a estrutura terminológica técnico-científica para composição de um vocabulário específico formando um corpus teórico dos meios de hospedagem, bem como construir um tesauro próprio à utilização no PIC Senac 2014-2018.

Conforme Faria e Pericão (2008, p. 729), “[...] vocabulário é o repertório que inventaria os termos de uma determinada área e que descreve, sob a forma de sucinta definição ou de ilustração, os dados por eles designados.". Nesse sentido, tem-se que vocabulário tecnológico é um conjunto de termos próprios de domínios que ligam aspectos científicos e técnicos (FARIA; PERICÃO, 2008).

Nessa perspectiva, seguindo a visão de Barros (2004), uma terminologia torna-se abrangente quando estão contempladas uma multidisciplinaridade no que diz respeito à transmissão de conhecimentos sobre uma diversidade de temas. A terminologia meios de hospedagem apresenta definições que contemplam a abrangência do tema. Porém, nem sempre os conceitos ou definições relacionadas ao termo são compreendidos, gerando diversas reinterpretações. Esta constitui uma das dificuldades encontradas pelos pesquisadores da área, o que não foi diferente com os pesquisadores do PIC Senac 2014-2016. Em caráter de exemplo, atentamos para o termo meios de hospedagem, que por vezes é utilizado sinônimo de alojamento ou mesmo, setor de hotelaria. Desse modo, vimos a importância do presente estudo com vistas a construir uma conceituação específica ou, no mínimo, encontrar um significado único, específico, para os termos usuais que caracterizam os meios de hospedagem.

Este estudo contempla um conjunto de termos especializados acompanhado de definições relacionados ao domínio dos meios de hospedagem. Fornece algumas observações ontológicas e epistemológicas que irão contribuir com a construção do observatório de indicadores do Senac/SC e podem contribuir para futuras pesquisas na área.

\section{REFERENCIAL: CONCEITO, DEFINIÇÃO E SIGNIFICADO}

É importante referir que esses termos são muitas vezes sinônimos, ou seja, com significado equivalente. No entanto, têm conotações diferentes dependendo do contexto. Ao sistematizar em que consiste uma definição, conceito ou mesmo um significado abre-se espaço ao 
leitor ampliando-se sua compreensão a respeito destes termos no intuito de observar as diferenças.

Para Bramont (2010), a definição delimita e por meio dela, tentamos apresentar algo de forma precisa por meio de palavras.

Já Arrabal (2013) descreve que:

Na Definição, tenta-se dizer o que algo é a partir da determinação da singularidade do objeto, ou seja, busca-se descrever aquilo que o objeto investigado tem de específico e distinto em relação aos demais. Uma Definição descreve a qualidade, característica ou substância sem a qual o objeto deixa de ser o que "é", em qualquer circunstância. De certa forma, trata-se de uma caracterização endógena e pretensamente universal do objeto pesquisado.

Desse modo, definição representa a compreensão de um conceito que torna os termos mais distintos, separando aquilo que não é, daquilo que é. As definições das palavras sempre devem, portanto, combinar com a linguagem usual. Qualquer que seja a área da ciência em que se enquadre a pesquisa, esta deve ser dirigida a todo tipo de leitor/receptor e não somente ao leitor de determinada área do conhecimento. Uma definição é adequada quando propicia suficientes características essenciais por meio das quais seja possível relacionar o termo em causa com a referência correspondente.

Definir, assim, consiste em determinar a extensão e a compreensão de um objeto ou abstração. Enunciar, dentro de um limite demarcado, os atributos essenciais e específicos do definido, tornando-o inconfundível. Em geral uma definição é a releitura, a luz de uma teoria, de um certo número de elementos do mundo real. É, portanto, uma interpretação, uma explicação.

Conceito é o objeto do conhecimento consciente em relação ao seu significado, que o distingue de outros objetos do conhecimento, pois existem duas qualidades básicas: abstração e generalização, onde sua propriedade pode ser atribuída a vários objetos (FACHIN, 2005).

No que tange ao conceito, cabe ainda dizer que este:

Também é uma tentativa de delimitação, porém, neste caso há um esforço em estabelecer "o ponto de vista" por meio do qual o objeto é reconhecido. Busca-se determinar um "contexto" para delinear o objeto. Ou seja, no Conceito, algo "é" a partir de um determinado meio físico, social ou teórico. Ao estabelecer um Conceito, o pesquisador descreve o objeto em razão e a partir de um entre inúmeros cenários contextuais possíveis. (ARRABAL, 2013).

De acordo com Abbagnano (1998, p. 907-908) entende-se por significado "a dimensão semântica do procedimento semiológico, ou seja, a possibilidade de um signo referir-se a seu objeto".

Para tanto, segundo o autor, há dois aspectos (ou condições) fundamentais ao significado. São eles: "1 - um nome, um conceito ou uma essência (p. ex., "Alessandra Manzoni", "homem", "autor de Os noivos"), usados com a finalidade de delimitar e orientar a referência; 2 - o objeto (p. ex., respectivamente, Alessandra Manzoni, os homens, Alessandra Manzoni), ao qual o nome, o conceito ou a essência se referem" (ABBAGNANO, 1998, p. 908).

Ele complementa destacando que ambos os aspectos são inseparáveis; o segundo é função do primeiro porque é o nome ou conceito que determina a que objeto se faz ou não referência.

Ao termo significado, ainda segundo Abbagnano (1998), corresponde também a conotação, chamando-se de denotação a referência objetiva (ou literal). Conforme o autor, "sempre que os nomes dados aos objetos comportam alguma informação, ou seja, sempre que, propriamente, têm um significado. Este, contudo, " não reside naquilo que eles denotam, mas 
naquilo que eles conotam. Os únicos nomes de objetos que nada conotam são os nomes próprios; estes, a rigor, não têm significação" (ibid.).

Após a análise dos três termos, a definição foi a opção escolhida para ser utilizada no tesauro pelo fato de descrever especificamente e com distinção o que o objeto investigado tem em relação aos demais, tentando apresentar assim, algo de forma precisa por meio de palavras. Daí a fundamental importância de o pesquisador, antes de executar sua pesquisa, conhecer bem o que vai medir ou provar e qual a operação de medida conceitual.

\subsection{O que é um tesauro, glossário ou terminologia de definições?}

Tesauro é conhecido como um dicionário de ideias afins. É uma lista de palavras com significados semelhantes dentro de um domínio específico. De acordo com Rejowski (2011), a palavra tesauro tem origem do latim thesaurus e significa tesouro. O tesauro gerencia os sistemas de classificação bibliográfica que surgiram estimulados pela necessidade de manipulação de grande quantidade de documentos e conteúdos especializados.

Os tesauros constituem-se em uma ferramenta de indexação já consolidada nas atividades de uma organização. $O$ estudo dos tesauros envolve diversos campos do conhecimento, pois o tema é, em si, multidisciplinar. Como área de estudo da Ciência da Informação, multidisciplinar por natureza e interdisciplinar na vocação, o tesauro herda dessa ciência tais propriedades.

Elaborar um tesauro é antes de tudo uma atividade intelectual, que requer o conhecimento de documentos produzidos na área, o entendimento dos termos empregados e a construção de conceitos para explicação dos termos. A construção de um tesauro requer uma atitude flexível para incorporar as mudanças que a linguagem utilizada sofre no caminho de seu desenvolvimento sem abrir mão dos conceitos, mas em atitude aberta a seu próprio desenvolvimento. Cada palavra, ou expressão recebe então o nome de termo, o qual equivale a um conceito adicionado de uma designação, construída por uma unidade léxica. Esses termos são um conceito que são denominados também de descritores, os outros chamam-se de não descritores e formam um conjunto das remissivas.

Para Moreira e Moura (2006), são essas características que fazem do tesauro um instrumento forte para identificar e recuperar informação armazenada em sistemas de informação como: bases de dados bibliográficos, repositórios de artigos e trabalhos acadêmicos e bibliotecas. Os tesauros começaram a ser elaborados a partir da constatação de que são várias as possibilidades de nomear fatos, processos, fenômenos ou objetos.

Porém, não se pode ter a ilusão de que um tesauro possa ser útil a todos igualmente, tem que ser direcionado a um público-alvo, pois assim ele será útil e terá a importância de identificar e selecionar termos que representem a necessidade da informação do usuário e consequentemente a utilização do material a ser incluído.

Moreira e Moura (2006) dizem, ainda, que o tesauro é algo eficaz, em contínua transformação, requerendo sucessivas atualizações. O objetivo do tesauro é representar os contextos dos documentos e das solicitações de procura. Esta reprodução é feita no momento da relação, por meio de processos contínuos de análise do documento, identificação de seu conteúdo e da tradução para os termos do tesauro de acordo com a política de indexação.

Na recuperação de uma definição, a solicitação é feita a partir do momento em que o indivíduo procura uma informação, sendo esta analisada, identificando-se seu conteúdo. A própria composição do tesauro, ou seja, os relacionamentos nele existentes permitem um processo de 
tradução. Um tesauro pode, ainda, assessorar na normalização de um dicionário, em caso de empregar algum vocabulário controlado.

Pelo exposto, é possível perceber que o tesauro tem vantagens e desvantagens sendo que, no decorrer da elaboração de algumas traduções, podem ser descobertas várias contrapartidas, mas notar vários termos distintos. Portanto, estes tendem de ser demonstrados a partir da informação dos profissionais e das definições no dicionário, frequentemente através de paráfrases.

Já o glossário é um acervo de termos de um espaço do conhecimento, exibidos em ordem metódica ou alfabética, seguidos de informação gramatical e definição. Com essa inteligência, os glossários são ferramentas que facilitam o acesso ao conhecimento e requerem o aprimoramento da comunicação. Os glossários são ampliados para aliar os conhecimentos necessários constituindo a nomenclatura a ser incluída, desenvolvendo as definições dos termos de modo mais adequado a fim de caracterizar o produto.

Identifica-se como glossário o técnico e o científico, já que, na ampliação das atividades, a técnica normalmente antecede à ciência e observa os desempenhos frequentes, onde confirma hipóteses apanhadas, e no estabelecimento de teorias, são frutos dos estudos científicos que confirmam a relevância de tal ciência. Sendo assim, o acesso da área prática para a teórica acontece de forma sútil entre o final de uma e o início da outra, até a nova ciência se estabelecer como tal. As áreas técnicas estão submersas na fase de tentar resolver problemas tópicos, objetivos para a rotina de temas no qual estão alistados. Como ainda não se tem um apoio científico que sancione sua precisão, tais áreas estão avaliando as melhores opções e aprimorando sua funcionalidade.

Em torno do vocábulo glossário, Vidovix (2014, p. 15), define: "lista ordenada que apresenta a tradução, definição e utilização exata de termos técnicos, desconhecidos ou centrados em um determinado campo de estudo, em nosso caso o trade turístico".

Em torno do tesauro, cabe dizer que este é uma maneira de navegação eficaz para a busca de definições. Contudo, é uma forma ainda pouco aproveitada. Baseia-se na ideia de proporcionar acesso às informações que podem ter semelhanças umas com as outras ou dependentes. Essa condição trabalha de acordo com o abastecimento de dados aos conteúdos publicados. Seu efeito é fornecer a qualquer pessoa um ingresso seguro à determinada informação.

Como foi ressaltado, o tesauro é um vocabulário controlado, empregado tanto para auxiliar no procedimento de consultas, buscas realizadas, como pelo indexador durante o processo de categorização e relação de assuntos. Devido a sua composição de termos e suas relações, o tesauro nos ajuda a descobrir o melhor termo que importa de um assunto desejado.

Nesse contexto, tesauro se manifesta como um elemento de grande importância em um sistema de recuperação das informações, pelo fato de desempenhar o papel de definir qual ou quais os termos podem ser usados na entrada do sistema ou em sua saída, apontando uma indexação ou procura com resultados suficientes para permitir a iniciação de novos termos em sua estrutura. Enfim, o tesauro tem como objetivos fundamentais indexar, armazenar e recuperar informações essenciais à temática abordada pelo mesmo, com vistas a promover o acesso rápido e fácil do usuário.

Após a arrecadação dos termos, são respondidas as fichas que se repetem com vistas a formar a melhor definição para o termo coletado para a área em estudo. Quando já estiver constituída qual a melhor definição, são estabelecidas as fichas sínteses.

É importante perceber, entretanto, que este não é um trabalho final. Não é um trabalho que se concretiza e se termina, pois a partir do momento que se edifica um tesauro, o mesmo deve manter-se atualizado, caracterizando sua relação com a realidade. Isso porque os termos e os significados estão em constante transformação. No tesauro aqui construído, foram considerados os 
termos mais empregados para o turismo, sendo que os mesmos necessitam de constantes atualizações, assim como os tesauros de outras áreas de conhecimento.

\section{METODOLOGIA PARA A CONSTRUÇÃO DE UM TESAURO}

Percorremos diversas fontes de informação escrita (livros, artigos, dicionários) de modo que os termos utilizados no turismo e hotelaria ficassem em evidência no tesauro servindo de fonte de pesquisa para estudantes e profissionais da área.

Assim, como é característico da construção de um processo de pesquisa, dúvidas surgiram o que foi importante para consolidar a pesquisa, a reunião e discussão dos participantes do estudo.

Nessa perspectiva, para fins do presente artigo, utilizamos a pesquisa bibliográfica como referência e subsídio para a construção do tesauro, caracterizando-o, como já pontuado anteriormente, como um conjunto ordenado de procedimentos por busca de soluções, atento ao objeto de estudo, e que, por isso, não pode ser aleatório (REJOWSKY, 2011)

Minayo (1994, p. 23 apud LIMA; MIOTO, 2007) cita que a pesquisa pode ser entendida como um processo no qual o pesquisador tem "uma atitude e uma prática teórica de constante busca que define um processo intrinsecamente inacabado e permanente", pois realiza uma atividade de aproximações sucessivas da realidade, sendo que esta apresenta "uma carga histórica" e reflete posições frente à realidade.

\section{TESAURO DOS MEIOS DE HOSPEDAGEM: CONJUNTO DE TERMOS PADRÃO DO PIC SENAC 2014-2016}

A seguir, apresentam-se alguns dos termos trabalhados no tesauro de definições. Este servirá como o conjunto de termos-chave utilizados no projeto, bem como se constituirá em uma fonte unívoca de definições trabalhadas na área de Turismo e Hospitalidade.

Dentre as fontes recentes pesquisadas, está Vidovix (2014), em cuja obra constam diversas definições ligadas à área de Turismo e Hospitalidade. Nesse contexto, resgatamos também a dissertação de Momm (2009), que se refere ao cenário turístico nacional e sulista, considerando-a uma referência importante na área estudada.

No Quadro 1, apresentamos o tesauro da área de Turismo e Hotelaria, resultado da pesquisa empreendida para fins desse artigo.

Quadro 1 - Termos mais utilizados

\begin{tabular}{|l|l|}
\hline \multicolumn{1}{|c|}{ TERMO } & \multicolumn{1}{c|}{ DEFINIÇÃO } \\
\hline Check-in & $\begin{array}{l}\text { Momento em que o hóspede faz seu cadastro para a hospedagem no } \\
\text { estabelecimento. }\end{array}$ \\
\hline Check-out & Momento em que o hóspede encerra sua hospedagem no estabelecimento. \\
\hline Meia Pensão & Hospedagem incluindo duas refeições (café da manhã, almoço ou jantar). \\
\hline Diária & $\begin{array}{l}\text { Valor cobrado pela hospedagem de até } 24 \text { horas em estabelecimento de } \\
\text { hospedagem. }\end{array}$ \\
\hline
\end{tabular}




\begin{tabular}{|l|l|} 
Deadline & Prazo estipulado para pagamento da reserva de hospedagem. \\
\hline No show & $\begin{array}{l}\text { Cancelamento da hospedagem sem reembolso pelo não comparecimento do } \\
\text { hóspede na data estipulada. }\end{array}$ \\
\hline Voucher & $\begin{array}{l}\text { Documento emitido ao hóspede pelas empresas de viagem, com objetivo de } \\
\text { autorizar despesas integrais ou parciais. }\end{array}$ \\
\hline
\end{tabular}

Fonte: Elaborada pelos autores (2016)

Foram identificados e definidos 226 termos para a constituição do tesauro. Nesse construto, destacamos alguns termos curiosos (Quadro 2).

Quadro 2 - Termos curiosos

\begin{tabular}{|l|l|}
\hline \multicolumn{1}{|c|}{ TERMO } & \multicolumn{1}{c|}{ DEFINIÇÃO } \\
\hline Ammenities & $\begin{array}{l}\text { Kit de toalha e higiene pessoal disponível nas unidades habitacionais } \\
\text { (UH). }\end{array}$ \\
\hline Back of the house & Áreas não expostas ao público, de circulação restrita aos funcionários. \\
\hline European plan (EP) & $\begin{array}{l}\text { Tipo de diária sem nenhum serviço de alimentação, apenas } \\
\text { hospedagem. }\end{array}$ \\
\hline Handicapped Room & $\begin{array}{l}\text { Unidade habitacional (UH) adaptada e preparada para hóspedes com } \\
\text { necessidades especiais. }\end{array}$ \\
\hline Layover & $\begin{array}{l}\text { Acomodação especial utilizada em imprevistos (problemas técnicos, } \\
\text { atrasos). }\end{array}$ \\
\hline Meeting facilities & $\begin{array}{l}\text { Instalações e equipamentos existentes no hotel para atendimentos de } \\
\text { eventos, convenções e reuniões. }\end{array}$ \\
\hline Overbooking & Reservas feitas além da capacidade de hospedagem. \\
\hline
\end{tabular}

Fonte: Elaborada pelos autores (2016).

Ao observarmos o Quadro 2, chama a atenção termos que são pouco usuais para a maior parte das pessoas que não se relacionam com área de turismo e hotelaria.

\section{CONSIDERAÇÕES FINAIS}

Para a conclusão do presente artigo, nos deparamos com algumas situações que fazem parte de quem investe em pesquisa. A proposta para a rede hoteleira era uma entrevista para facilitar o entendimento do glossário, visando também tirar outras dúvidas relativas ao meio hoteleiro. Encontramos dificuldades junto aos funcionários ao entrevistar três hotéis diferentes, a resposta era a mesma dada pelos funcionários: a falta de tempo e o fato de não terem um profissional responsável no controle do próprio hotel.

A ideia era que conhecêssemos termos de uso corrente e aqueles que, de fato, não têm uso frequente nos meios de hospedagem. Isso porque nem sempre seus conceitos e definições se apresentam com uniformidade. Daí a importância de compor um tesauro de definições. Trabalhar com definições, nas quais os termos têm um sentido delimitado, torna-se mais seguro tendo em vista o objetivo deste trabalho (compor uma terminologia unívoca para o PIC Senac 2014-2016 e para demais pesquisas na área).

A partir disso, materializamos a investigação percorrida por meio de um caminho seguro, a qual foi ampliada a compreensão sobre a pesquisa em foco. Assim, percebemos a importância de discutir a esse estudo da área de turismo e hotelaria, percorrendo um caminho de unicidade, sem divisão de ideias e possibilitando a compreensão das terminologias considerando suas especificidades. 


\section{REFERÊNCIAS}

ABBAGNANO, Nicola. Dicionário de Filosofia. Tradução de Alfredo Bosi. 21. ed. São Paulo: Martins Fontes, 1998.

ARRABAL, Alejandro K. Existe diferença entre definição e conceito? [2013]. Disponível em: $<$ http://www.praticadapesquisa.com.br/2013/02/existe-diferenca-entre-definicao-e.html>. Acesso em: 16 abr. 2015.

BARROS, L. A. Curso básico de terminologia. São Paulo: Editora da Universidade de São Paulo, 2004.

BRAMONT, Pedro. Fuja das definições. Prefira os conceitos. [2010]. Disponível em: $<$ http://webinsider.com.br/2010/04/17/fuja-das-definicoes-prefira-osconceitos/\#sthash.PFFPg6tN.dpuf>. Acesso em: 16 abr. 2015.

FACHIN, Odélia. Fundamentos de Metodologia. 3. ed. São Paulo: Saraiva, 2005.

FARIA, Maria Isabel; PERICÃO, Maria da Graça. Dicionário do livro: da escrita ao livro eletrônico. São Paulo: EdUsp, 2008

LIMA, Telma Cristiane Sasso; MIOTO, Regina Célia Tamaso. Procedimentos metodológicos na construção do conhecimento científico: a pesquisa bibliográfica. [2007]. Disponível em: <http://www.scielo.br/pdf/rk/v10nspe/a0410spe>. Acesso em: 23 abr. 2015.

MOMM, Christiane F. O conhecimento científico em Turismo no Brasil: cursos de pós- graduação (stricto sensu) - período de 2000 a 2006. 2009. 131 f. Dissertação (Mestrado em Ciência da Informação) - Universidade Federal de Santa Catarina, Florianópolis, 2009.

MOREIRA, Manoel P.; MOURA, Maria A. Construindo tesauros a partir de tesauros existentes: a experiência do TCl - Tesauro em Ciência da Informação. [2006]. Disponível em: <http://www.dgz.org.br/ago06/Art_01.htm>. Acesso em: 16 abr. 2015.

REJOWSKI, Miriam. Subsídios para elaboração de um Tesauro Brasileiro de Turismo. [2011]. Disponível em: <http://www.turismoemanalise.org.br/turismoemanalise/article/view/247>. Acesso em: 23 abr. 2015

VIDOVIX, Sílvia. O Quê? What? Uot? - terminologias do turismo, hotelaria, aviação, A\&B e afins. Rio de Janeiro: Qualitymark, 2014. 